\title{
PENGARUH KUALITAS JASA PERGURUAN TINGGI TERHADAP KEPUASAN DAN LOYALITAS MAHASISWA
}

\author{
Widya Iswara \\ Luki Adiati Pratomo \\ Luki.adiati@trisakti.ac.id
}

Fakultas Ekonomi, Universitas Trisakti, Jakarta, Indonesia

\begin{tabular}{l} 
Info Artikel \\
\hline Sejarah Artikel: \\
Diterima \\
Disetujui \\
Dipublikasikan \\
\hline Keywords: \\
academic aspects, access, \\
non-academic aspects, \\
program issues, \\
reputation, student \\
satisfaction, university \\
image, student loyalty.
\end{tabular}

\begin{abstract}
Abstrak
Tujuan dari penelitian ini adalah untuk menganalisa pengaruh kualitas jasa terhadap kepuasan dan loyalitas mahasiswa serta citra Perguruan Tinggi. Data diperoleh dengan cara menyebarkan kuisioner kepada 120 responden yaitu mahasiswa Universitas Trisakti. Data yang digunakan adalah data cross-sectional dan menggunakan purposive sampling sebagai metode pegambilan sampel. Alat analisis yang digunakan adalah Structural Equation Modeling (SEM). Hasil pengujian hipotesa menunjukkan bahwa aspek akademis, aspek non akademis dan reputasi berpengaruh positif terhadap kepuasan mahasiswa, sedangkan aspek program dan akses tidak mempunyai pengaruh positif terhadap kepuasan mahasiswa. Kemudian kepuasan mahasiswa juga mempunyai pengaruh positif terhadap citra perguruan tinggi sementara kepuasan mahasiswa dan citra ternyata tidak mempunyai pengaruh positif terhadap loyalitas mahasiswa. Disarankan bagi Universitas Trisakti untuk memperkuat reputasi yang merupakan faktor terpenting dalam mempengaruhi kepuasan mahasiswa, serta mengembangkan strategi hubungan pemasaran agar dapat meningkatkan loyalitas mahasiswa. Untuk penelitian selanjutnya disarankan mengevaluasi penetapan harga (price fairness) dalam mencapai kepuasan dan loyalitas mahasiswa. .
\end{abstract}

\section{THE INFLUENCE OF HIGHER EDUCATION SERVICE QUALITY TOWARD STUDENT SATISFACTION AND LOYALTY.}

\begin{abstract}
The purpose of this study is to analyze the impacts of higher education service quality towards student satisfaction and Loyalty, and student satisfaction towards university image and student loyalty. The data was gathered using questionnaires and was collected from 120 respondents who study at Trisakti University. The data was using cross-sectional and the sampling method was using purposive sampling. This research were using Structural Equation Modeling (SEM) as analysis method.The finding shows that academic aspects, non-academic aspects and reputation influenced students satisfaction while program issues and access did not have impact on students satisfaction. The other results proved that students satisfaction influence University image but surprisingly students satisfaction and University image did not have impact on students loyalty. Very important for Trisakti University to improve their image because this is one strong factor in building students satisfaction, while they have to develop customer relationship management with their students and alumni to strengthen their students loyalty. To understand more student satisfaction, it advised to examine the price fairness as one possible factor in building students satisfaction and loyalty.
\end{abstract}

\footnotetext{
Alamat korespondensi : 


\section{PENDAHULUAN}

Persaingan antar perguruan tinggi (PT) di Indonesia semakin ketat. Sesuai laporan dari Dirjen Dikti per tahun 2016, jumlah PT Swasta adalah 3940 dan jumlah PT Negeri sebanyak 372 (Dirjen Kelembagaan IPTEK dan DIKTI, 2016). Persaingan yang ketat tersebut menyebabkan perguruan tinggi harus memikirkan strategi yang tepat agar dapat bertahan dan juga mengembangkan diri.

Perguruan Tinggi sebagai salah satu bagian dari industri jasa, mau tidak mau harus memperhatikan kualitas jasa yang mereka sampaikan pada mahasiswa agar dapat memuaskan mereka (Ali, Zhou, Hussain, Nair \& Ragavan, 2014).

Untuk menarik konsumen baru dan mempertahankan konsumen lama, PT harus mengembangkan keunggulan kompetitif yang berfokus pada kualitas jasa mereka (Helgesen \& Nesset, 2007). Abdullah (2005) mengembangkan lima dimensi untuk mengukur kualitas layanan pada PT yaitu Higher Education Performance (HEdPERF), yang mencakup (1) pelayanan akademik (2) pelayanan non-akademik (3) pelayanan akses (4) program-program yang tersedia, dan (5) reputasi.

Kelima dimensi tersebut akan membentuk kepuasan mahasiswa dan menghasilkan image (citra) PT yang baik dan pada akhirnya akan menciptakan kesetiaan mahasiswa (Abdullah, 2005 dan Ali, Zhou, Hussain, Nair, \& Ragavan, 2016). Konsumen yang setia adalah mereka yang tetap bersedia membeli produk atau jasa perusahaan secara berulang, bahkan dapat merekomendasikannya kepada teman dan kerabat (Xiaoyun Han, Kwortnik, \& Chunxiao Wang, 2008).

Kepuasan mahasiswa terhadap PT tempat mereka kuliah akan menyebabkan mereka mempunyai sikap yang positif terhadap PT tersebut bahkan setelah setelah mahasiswanya lulus kuliah dan menjadi alumni (Baruch \& Sang, 2012).

Menyadari hal tersebut, maka sangat penting bagi PT untuk membuat mahasiswanya puas agar mereka setia (student loyalty) sekaligus membuat citra (image) PT menjadi bagus dimata mahasiswa. Oleh karenanya PT perlu memahami kualitas jasa pada perguruan tinggi yang terdiri dari academic aspects, non-academic aspects, program issues, reputation, access (Abdullah, 2005).

Banyak penelitian sebelumnya yang telah mengevaluasi faktor apa saja yang dapat mendorong kepuasan mahasiswa, tetapi belum banyak yang menggunakan instrument kualitas jasa yang dikembangkan Abdulah (2005) untuk memahami peranan kualitas jasa untuk kepuasan mahasiswa, khususnya di Universitas Trisakti.

Oleh sebab itu, penelitian ini bertujuan untuk mengetahui peranan kualitas jasa dalam mendorong kepuasan mahasiswa, dan bagaimana kepuasan akan mendorong citra PT yang baik juga loyalitas mahasiswa terhadap PT. Selain itu, penelitian ini ingin mengetahui faktor apa yang paling penting sehingga PT, khususnya Universitas Trisakti dapat meningkatkan pelayanannya kepada mahasiswa agar kepuasan dapat tercapai.

\section{TELAAH PUSTAKA}

Kualitas Jasa pada Perguruan Tinggi

Perguruan Tinggi sebagai sebuah usaha jasa, baik swasta maupun negeri harus menyampaikan pelayanan yang berkualitas untuk konsumennya yaitu mahasiswa (Sultan \& Yin Wong, 2013). Beberapa peneliti telah melakukan studi mengenai 
pentingnya kualitas jasa pada perguruan tinggi dengan menggunakan berbagai instrument penelitian seperti SERVQUAL (Smith, Smith, \& Clarke, 2007), kemudian (Brochado, 2009) menggunakan SERVPERF dan juga (Abdullah, 2006b) menggunakan HEdPERF.

Abdullah, (2006b) mengembangkan lima dimensi khusus untuk mengukur kualitas layanan PT atau Higher Education Performance (HEdPERF).

Dimensi pertama adalah pelayanan akademik (academic aspects), merupakan aspek yang menekankan pada kemampuan staff pengajar dalam menjawab pertanyaan mahasiswa. Selain itu juga kemampuan komunikasi staff pengajar dengan mahasiswa.

Dimensi kedua yaitu pelayanan non-akademik (non academic aspects), adalah aspek pelayanan staff administrasi. Diharapkan staff administrasi memiliki pengetahuan mengenai sistem perkuliahan, mampu memenuhi permintaan mahasiswa dengan segera dan mampu menjaga kerahasiaan informasi mahasiswa.

Dimensi ketiga adalah pelayanan akses (access). Dimensi ini menjelaskan bahwa diharapkan staff akademik memiliki keinginan merespon permintaan mahasiswa dengan cepat dan memiliki pengetahuan mengenai perkuliahan sehingga dapat menanggapi permintaan mahasiswa dengan baik dan tepat.

Dimensi keempat adalah program-program yang tersedia di universitas (program issues). Dimensi ini menekankan pada program studi yang ditawarkan PT memiliki struktur yang fleksibel. Selain itu diharapkan PT memiliki berbagai jurusan (program studi) yang berkualitas. Dimensi kelima ialah reputasi (reputation). Dimensi ini menggambarkan citra yang baik dan professional serta kemudahan alumni untuk mendapatkan pekerjaan.

Menurut Abdullah (2006) dan Ali et al., (2014) sangat penting bagi PT untuk melaksanakan pelayanan kepada konsumennya yaitu mahasiswa dengan menyampaikan ke lima dimensi tersebut dengan baik agar kepuasan mahasiswa dapat tercapai. Begitu juga (Sharif \& Kassim, 2012) menjelaskan bahwa kualitas jasa dalam bentuk nonakademik sangat mempengaruhi kepuasan mahasiswa.

\section{Student Satisfaction}

Kepuasan konsumen merupakan tujuan penting bagi perusahaan Karena kepuasan akan menghasilkan loyalitas konsumen (R. Oliver, 1999). Begitu juga PT harus memuaskan konsumennya yaitu mahasiswa agar tercapai loyalitas dari mahasiswa, bahkan setelah mereka menjadi alumni (Baruch \& Sang, 2012). Banyak penelitian telah membuktikan bahwa kepuasan mahasiswa akan meningkatkan loyalitas mereka dan juga akan membuat citra PT menjadi semakin baik dimata mahasiswa dan alumninya (Nguyen \& LeBlanc, 2001) (Baruch \& Sang, 2012) (Petruzzellis et al., 2013).

\section{Student Loyalty}

Konsumen yang loyal menjadi sangat penting bagi perusahaan dan hal tersebut dapat tercapai bila konsumen puas terhadap perusahaan (Xiaoyun Han et al., 2008). PT sebagai usaha jasa juga harus dapat memuaskan konsumen yang akan mendorong loyalitas konsumen. Banyak penelitian telah membuktikan bahwa mahasiswa yang puas akan loyal sampai mereka sudah menjadi alumni (Nguyen \& LeBlanc, 2001) Helgesen 
dan Nesset, (2007) juga membuktikan bahwa loyalitas mahasiswa dibentuk oleh dua faktor yaitu kepuasan siswa dan kinerja universitas.

Image

Image atau citra menurut (Azoury, Daou, \& Khoury, 2014) adalah keyakinan, ide, perasaan dan impresi seseorang mengenai sebuah insititusi atau organisasi pada suatu saat tertentu. Sedangkan citra suatu PT menurut (Arpan, Raney, \& Zivnuska, 2003) adalah keseluruhan kesan yang dirasakan mahasiswa setelah mereka belajar pada PT tersebut.

Berdasarkan pendapat tersebut, maka citra PT menjadi salah satu hasil dari kepuasan mahasiswa yang telah menikmati jasa dari PT tersebut. Beberapa peneliti telah membuktikan bahwa ketika mahasiswa merasa puas terhadap pelayanan yang diperoleh selama belajar di suatu PT, maka hal itu akan membentuk image yang baik dibenak mahasiswa (Nguyen \& LeBlanc, 2001) (Alves \& Raposo, 2010) (Azoury et al., 2014).

\section{Pengembangan Hipotesis}

Selama masa kuliah, mahasiswa akan menilai pelayanan yang diberikan PT dan mereka akan menyimpulkan seberapa baik service quality dari PT tersebut (Jancey dan Burns, 2013). Mereka akan menilai akademik aspek seperti kemampuan pengajar dalam menyampaikan materi perkuliahan, kemampuannya dalam berkomunikasi dengan mahasiswa dan interaksinya dengan mahasiswa (DeShields, Kara, \& Kaynak, 2005). Mereka menjelaskan bahwa semakin baik aspek akademis dari pengajar, maka semakin baik pengalaman mereka selama berkuliah dan menyebabkan kepuasan mereka meningkat (DeShields et al., 2005). Begitu juga hasil penelitian Abdullah (2005) yang menegaskan bahwa aspek akademik sangat penting dalam meningkatkan kepuasan mahasiswa. Sehingga semakin baik kualitas para staff mengajar akan berdampak pada meningkatnya kepuasan mahasiswa (Ali et al., 2016). Berdasarkan beberapa teori diatas, dapat dikembangkan hipotesa sebagai berikut :

H1: Academic Aspects berpengaruh positif terhadap Student Satisfaction

Selain faktor akademis, berdasarkan penelitian yang dilakukan Abdullah (2005) dan (Abdullah, 2006a) kepuasan mahasiswa juga di pengaruhi oleh faktor nonakademis. Hal tersebut didukung oleh Kuh \& Hu (2001) yang menyatakan bahwa kepuasan mahasiswa dipengaruhi secara signifikan oleh interaksi yang efektif antara pihak universitas dengan mahasiswanya. Untuk mendukung hal tersebut, faktor nonakademis seperti peran staff administrasi juga sangat penting untuk meningkatkan kepuasan mahasiswa. Semakin baik kualitas para staff akademis akan berdampak pada meningkatnya kepuasan mahasiswa (Ali et al., 2016). Berdasarkan beberapa teori diatas, dapat dikembangkan hipotesa sebagai berikut :

H2: Non-Academic Aspects berpengaruh terhadap Student Satisfaction

Faktor lain yang juga mempengaruhi kepuasan konsumen adalah programprogram yang ditawarkan oleh pihak Universitas (Alves \& Raposo, 2010). Jika Universitas menawarkan banyak program studi dengan kualitas yang baik dan struktur yang fleksibel serta memiliki berbagai program lainnya seperti pertukaran pelajar, beasiswa atau kursus keahlian tertentu, maka hal tersebut akan semakin meningkatkan 
kepuasan mahasiswa (EFFAZIELA MOHAMAD TAHAR, 2008). Begitu juga hasil penelitian Abdulah (2006) memastikan bahwa program yang ditawarkan PT merupakan salah satu factor yang akan memuaskan mahasiswa. Hal tersebut juga didukung oleh Ali et al., (2016) yang menyatakan bahwa terdapat pengaruh dari program issues terhadap student satisfaction. Dari uraian diatas dapat dirumuskan hipotesis sebagai berikut :

\section{H3: Program Issues berpengaruh terhadap Student Satisfaction}

Reputasi sebuah PT menentukan seberapa besar minat seseorang untuk mendaftar di PT tersebut (Sultan \& Yin Wong, 2013). PT yang memiliki reputasi yang baik akan memudahkan alumninya untuk mendapatkan pekerjaan (Petruzzellis et al., 2013). Sehingga berdasarkan penelitian yang dilakukan (Jancey \& Burns, 2013) semakin baik reputasi sebuah PT, maka akan semakin tinggi kepuasan yang dirasakan oleh mahasiswa PT tersebut. Berdasarkan beberapa teori diatas, dapat dikembangkan hipotesa sebagai berikut :

H4: Reputation berpengaruh terhadap Student Satisfaction

Kemudahan akses bagi mahasiswa ketika menghubungi pihak PT juga mempengaruhi penilaian mahasiswa terhadap PT (Sultan \& Yin Wong, 2010). Kemudahan akses yang ditawarkan oleh PT seperti kemudahan mahasiswa dalam menghubungi pihak PT, menyediakan waktu konsultasi dan pengajar maupun staff administrasi yang mempunyai pengetahuan yang mendalam mengenai PT tersebut (Sharif \& Kassim, 2012). Mereka menjelaskan bahwa ketika kemudahan akses tersedia dengan baik, maka mahasiswa akan puas dengan PT tersebut (Sharif \& Kassim, 2012). Ali et al., (2016) menyatakan bahwa semakin mudah akses yang diberikan oleh pihak universitas akan berdampak pada semakin tingginya tingkat kepuasan mahasiswa. Berdasarkan beberapa teori diatas, dapat dikembangkan hipotesa sebagai berikut :

H5: Access berpengaruh terhadap Student Satisfaction

Customer satisfaction merupakan evaluasi konsumen ketika mereka berpendapat bahwa kinerja produk atau jasa ternyata lebih baik dibandingkan harapannya pada saat mereka mengkonsumsi barang atau jasa tersebut (R. Oliver, 1999) (Han \& Ryu, 2009). Customer satisfaction merupakan salah satu factor yang membentuk citra (image) yang baik bagi suatu usaha (Nguyen \& LeBlanc, 2001) (Nguyen \& LeBlanc, 1998). Pada PT, kepuasan konsumen ternyata juga meningkatkan image dari PT tersebut. Hal ini sesuai dengan penelitian (Helgesen \& Nesset, 2007) yang menemukan bahwa kepuasan mahasiswa mempengaruhi image dari PT tersebut. Begitu juga (Alves \& Raposo, 2010) dan (Ali et al., 2016) menjelaskan bahwa semakin tinggi kepuasan mahasiswa, maka semakin baik image dari PT tersebut. Berdasarkan beberapa teori diatas, dapat dikembangkan hipotesa sebagai berikut :

H6: Student Satisfaction berpengaruh terhadap Image

(Alves \& Raposo, 2010) menjelaskan bahwa salah satu faktor yang mempengaruhi loyalitas konsumen adalah kepuasan konsumen. Peneliti-peneliti awal dalam bidang jasa menemukan bahwa semakin tinggi kepuasan konsumen, maka loyalitas konsumen juga akan semakin tinggi, sehingga mereka bersedia melakukan pembelian ulang dan menyampaikan berita positif mengenai jasa tersebut kepada orang lain (R. L. Oliver, Rust, \& Varki, 1997) (R. Oliver, 1999). Begitu juga mahasiswa yang 
merupakan konsumen sebuah PT, juga akan menjadi loyal ketika mereka puas, sebagaimana yang telah ditemukan oleh (Fernandes, Ross, \& Meraj, 2013) dan (Helgesen \& Nesset, 2007) dan (Dehghan, Dugger, Dobrzykowski, \& Balazs, 2014). Berdasarkan beberapa teori diatas, dapat dikembangkan hipotesa sebagai berikut :

H7: Student Satisfaction berpengaruh terhadap Student Loyalty

Citra yang baik dari sebuah PT akan meningkatkan loyalitas mahasiswanya (Nguyen \& LeBlanc, 2001). Hal itu sesuai dengan penelitian (Azoury et al., 2014) yang memastikan pentingnya citra (Image) dari PT, mengingat pengaruhnya yang significant terhadap loyalitas mahasiswanya. Begitu juga (Ali et al., 2016) pada penelitiannya di PT Malasyia menemukan bahwa image berpengaruh positif terhadap loyalitas mahasiswanya (Ali et al., 2016). Image dari kualitas jasa yang ditawarkan memiliki dampak yang kuat terhadap loyalitas konsumennya (Narteh, 2013). Berdasarkan beberapa teori diatas, dapat dikembangkan hipotesa sebagai berikut :

H8: Image berpengaruh terhadap Student Loyalty

\section{METODE}

Alat ukur dalam penelitian ini dikembangkan dari Ali et al., (2016), terdiri dari academic aspects, non-academic aspects, program issues, reputation, access, student satisfaction, image dan student loyalty. Semua variable diukur menggunakan 5 skala likert yang dimulai dari 1 "sangat tidak setuju" sampai 5 "sangat setuju" .

Pengumpulan data melalui penyebaran kuesioner tertulis kepada 150 responden dan akhirnya mendapatkan 120 yang dapat digunakan. Penarikan sampel menggunakan metode non probability sampling dengan teknik pengambilan sampel yaitu purposive sampling. Kriteria sampel dalam penelitian ini adalah mahasiswa-mahasiswi di Fakultas Ekonomi Universitas Trisakti.

Sebelum uji hipotesa, dilakukan pengujian instrument penelitian yang terdiri dari uji validitas dan uji reliabilitas. Uji validitas menggunakan Confirmatory Factor analysis. Berkaitan dengan jumlah sampel 120 maka indikator dengan nilai loading lebih besar dari 0,50 dinyatakan valid (Hair et al., 2010). Sedangkan pengujian reliabilitas menggunakan Internal Consistency Reliability Method dengan mengacu pada Cronbach's Alpha dengan koefisien 0,60 (Sekaran dan Bougie, 2010).

Berdasarkan hasil uji validitas, semua indikator mempunyai nilai antara 0,5 sampai 0.90 yaitu diatas 0.45 sehingga dapat dikatakan semua indikator penelitian ini valid. Begitu juga berdasarkan hasil uji reliabilitas, terlihat bahwa semua variable mempunyai nilai coefisien cronbach alpha diantara 0,66 sampai 0,91 yang berarti semua variable adalah reliable/konsisten.

Data diolah dan dianalisa dengan menggunakan Structural Equation Modelling (SEM). Sebelum pengujian hipotesis dilakukan lebih dahulu pengujian goodness of fits model untuk memastikan apakah model yang diajukan cocok dengan data. Berdasarkan table 1, terlihat bahwa model sudah sesuai dan pengujian hipotesa dapat dilaksanakan. 
Tabel 1 : Uji Kesesuaian Model

\begin{tabular}{|l|c|c|c|}
\hline Goodness of fit index & $\begin{array}{c}\text { Criteria } \\
\text { (cut-off value) }\end{array}$ & $\begin{array}{c}\text { Nilai } \\
\text { Indikator }\end{array}$ & Kesimpulan \\
\hline Chi-Square $\left(\mathrm{X}^{2}\right)$ & Mendekati 0 & 1364.804 & Poor Fit \\
\hline Probabilita & $\geq 0,05$ & 0.000 & Poor Fit \\
\hline NFI & $\geq 0.90$ & 0.603 & Poor Fit \\
\hline IFI & $\geq 0.90$ & 0.876 & Marginal Fit \\
\hline TLI & $\geq 0.90$ & 0.765 & Poor Fit \\
\hline CFI & $\geq 0.90$ & 0.781 & Poor Fit \\
\hline RMR & $\leq 0,10$ & 0.056 & Goodness of Fit \\
\hline RMSEA & $\leq 0,10$ & 0.077 & Goodness of Fit \\
\hline
\end{tabular}

Sumber : Data Primer yang diolah, 2016 


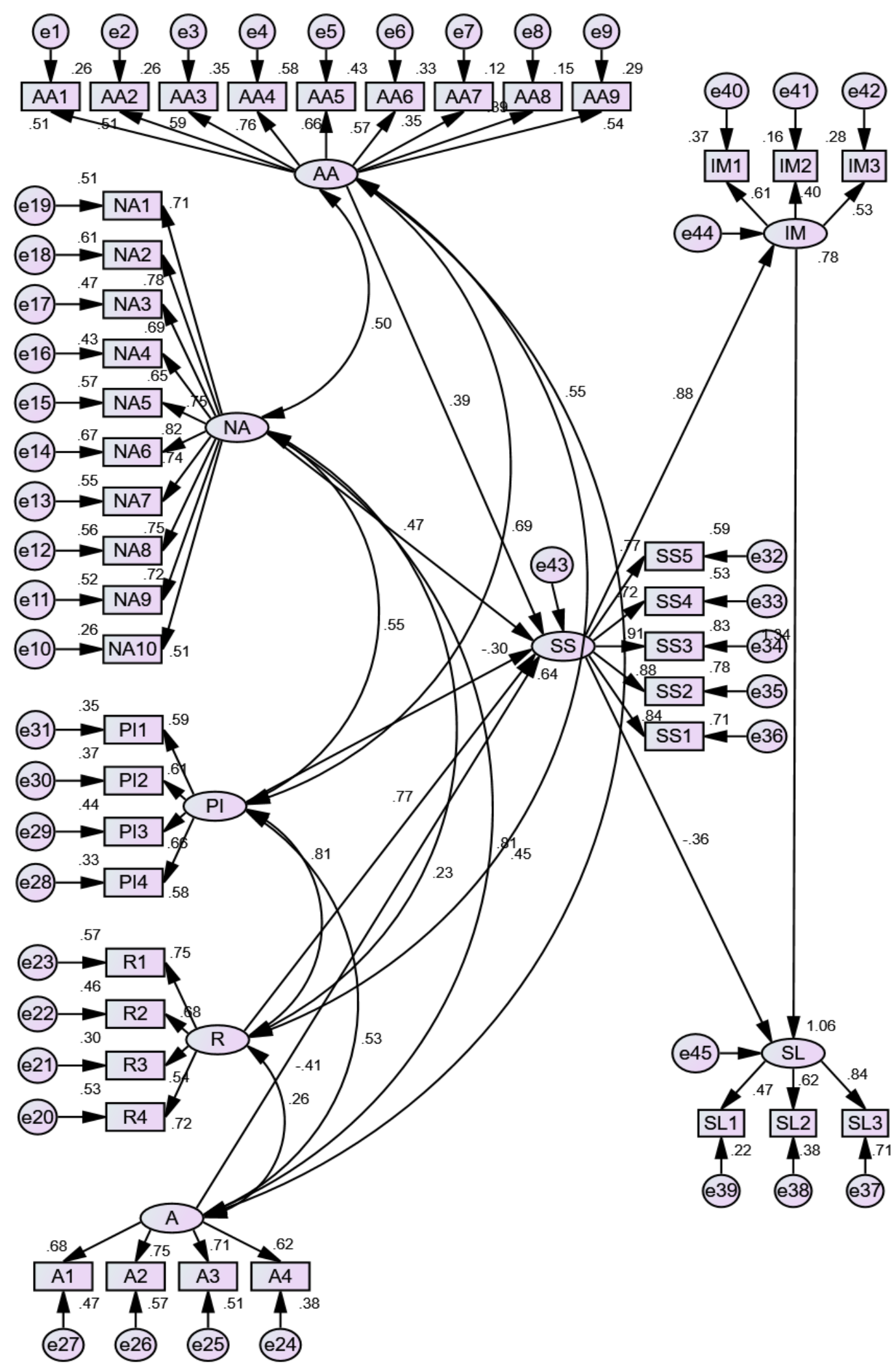

Gambar 1. Output Hasil Pengolahan AMOS 


\section{HASIL DAN PEMBAHASAN}

Setelah model dinyatakan sesuai, maka dilaksanakan pengujian hipotesa menggunakan SEM (Structural Equation Modelling). Dasar pengambilan keputusan uji hipotesa dengan membandingkan koefisien dengan tingkat signifikan sebesar 5\% $(\alpha=0,05)$. Semua hasil dinyatakan signifikan, karena hasil hipotesis $\leq 0,05$.

Tabel 2 : Hasil Uji Hipotesa

\begin{tabular}{|c|c|c|c|}
\hline Hipotesis & Estimate & $P$-value & Keputusan \\
\hline $\begin{array}{l}\text { H1: Academic } \quad \text { Aspects } \\
\text { berpengaruh positif signifikan terhadap } \\
\text { Student Satisfaction }\end{array}$ & 0,390 & 0,041 & $\begin{array}{c}\mathrm{H} 1 \\
\text { Didukung }\end{array}$ \\
\hline $\begin{array}{l}\text { H2: Non-Academic Aspects } \\
\text { berpengaruh positif signifikan terhadap } \\
\text { Student Satisfaction }\end{array}$ & 0,475 & 0,047 & $\begin{array}{c}\mathrm{H} 2 \\
\text { Didukung }\end{array}$ \\
\hline $\begin{array}{l}\text { H3: Program Issues berpengaruh } \\
\text { positif signifikan terhadap Student } \\
\text { Satisfaction }\end{array}$ & -0.299 & 0,506 & $\begin{array}{c}\mathrm{H} 3 \\
\text { Tidak Didukung }\end{array}$ \\
\hline $\begin{array}{l}\text { H4: Reputation berpengaruh } \\
\text { positif signifikan terhadap Student } \\
\text { Satisfaction }\end{array}$ & 0.768 & 0,021 & $\begin{array}{c}\mathrm{H} 4 \\
\text { Didukung }\end{array}$ \\
\hline $\begin{array}{l}\text { H5: Access berpengaruh positif } \\
\text { signifikan terhadap Student Satisfaction }\end{array}$ & -0406 & 0,053 & $\begin{array}{l}\text { H5 } \\
\text { Tidak Didukung }\end{array}$ \\
\hline $\begin{array}{l}\text { H6: Student Satisfaction } \\
\text { berpengaruh positif signifikan terhadap } \\
\text { Image }\end{array}$ & 0,883 & 0,000 & $\begin{array}{c}\text { H6 } \\
\text { Didukung }\end{array}$ \\
\hline $\begin{array}{l}\text { H7: Student Satisfaction } \\
\text { berpengaruh positif signifikan terhadap } \\
\text { Student Loyalty }\end{array}$ & $-0,364$ & 0,666 & $\begin{array}{l}\text { H7 } \\
\text { Tidak Didukung }\end{array}$ \\
\hline $\begin{array}{l}\text { H8: Image berpengaruh positif } \\
\text { signifikan terhadap Student Loyalty }\end{array}$ & 0,338 & 0,159 & $\begin{array}{c}\mathrm{H} 8 \\
\text { Tidak Didukung }\end{array}$ \\
\hline
\end{tabular}

Sumber : Data Primer yang diolah, 2016

Berdasarkan hasil pengujian hipotesa, ditemukan beberapa hal yang menarik yaitu dari delapan hipotesa, empat didukung yaitu akademik aspek, non akademik aspek dan reputasi mempunyai pengaruh positif terhadap kepuasan dan kepuasan mahasiswa mempunyai pengaruh positif terhadap image atau citra PT. Kemudian terdapat empat hipotesa yang tidak didukung yaitu program issues dan access ternyata tidak mempunyai pengaruh positif terhadap kepuasan mahasiswa lalu kepuasan mahasiswa dan image juga tidak mempunyai pengaruh positif terhadap loyalitas mahasiswa. 
Selanjutnya, apabila dilihat dari besarnya pengaruh, terlihat bahwa reputasi mempunyai pengaruh terbesar terhadap kepuasan mahasiswa dibandingkan peranan akademik dan non akademik factor. Hal ini merupakan salah satu temuan yang penting, Karena pada umumnya penelitian-penelitian sebelumnya menemukan bahwa akademik factor merupakan hal terpenting bagi mahasiswa (Ali et al., 2016).

Berdasarkan hasil pengujian hipotesis pertama, dapat disimpulkan bahwa Academic Aspects mempunyai pengaruh positif terhadap Student Satisfaction. Hal ini menunjukkan bahwa semakin baik aspek akademik seperti staff pengajar Universitas Trisakti yang mempunyai pengetahuan yang luas dan mampu berinteraksi dengan mahasiswa, maka kepuasan mahasiswanya juga akan meningkat. Hal ini menunjukkan bahwa mahasiswa memerlukan keyakinan bahwa staff pengajar harus mempunyai pendidikan yang sesuai dengan mata kuliah yang diajarkannya. Selain itu, mahasiswa menginginkan staff pengajar yang dapat diajak berkomunikasi dengan mudah, baik secara tatap muka maupun dengan menggunakan tehnologi yang sekarang sudah sangat populer seperti whatssup dan Line.

Hasil penelitian sesuai dengan (Hill, 1995) dalam exploratory research menemukan bahwa bagi mahasiswa tahun pertama, kedua dan ketiga kualitas dan metode mengajar merupakan factor yang sangat penting. Begitu juga pendapat dari (Sultan \& Yin Wong, 2013) yang menemukan bahwa mahasiswa ingin agar staff pengajar harus dapat berinteraksi dengan mereka, dapat menjelaskan sehingga mudah dimengerti dan mengajar dengan menyenangkan. Temuan ini juga mendukung dan sejalan dengan hasil penelitian yang dilakukan Ali et al., (2016) yang membuktikan bahwa akademik aspek merupakan faktor penting dalam meningkatkan kepuasan mahasiswa.

Selanjutnya berdasarkan hasil pengujian hipotesis kedua, dapat disimpulkan bahwa terdapat pengaruh positif antara Non-Academic Aspects dengan Student Satisfaction. Hal ini menunjukkan bahwa semakin baik pelayanan dari staff dan aspek non-akademik lainnya yang diberikan oleh Universitas Trisakti, terhadap mahasiswanya, maka akan meningkatan kepuasan mahasiswa. Terlihat bahwa pelayanan dari staff pendukung seperti bagian administrasi mempunyai pengaruh yang besar terhadap kepuasan mahasiswa. Temuan penelitian ini sesuai dengan (Sharif \& Kassim, 2012) yang memastikan bahwa mahasiswa menganggap pelayanan dari staff administrasi penting dan dapat meningkatkan kepuasan mereka. Begitu juga (Sultan \& Yin Wong, 2013) serta (Ali et al., 2016) memastikan bahwa non akademik aspek seperti empati dari staff administrasi akan meningkatkan kepuasan mahasiswa.

Sedangkan hasil pengujian hipotesis ketiga, ternyata memperlihatkan bahwa Program Issues tidak mempunyai pengaruh positif terhadap Student Satisfaction. Hal ini menunjukkan bahwa walaupun PT dalam hal ini Universitas Trisakti telah menyediakan banyak program studi, tetapi hal tersebut tidak meningkatkan kepuasan mahasiswa. Hal ini mungkin terjadi karena kebanyakan responden adalah mahasiswa Fakultas Ekonomi dan Bisnis yang tidak merasa memerlukan program studi yang lain.

Kemudian hasil pengujian hipotesis keempat memperlihatkan bahwa terdapat pengaruh positif antara Reputation $(0,768)$ dengan Student Satisfaction, bahkan mempunyai pengaruh yang terbesar dibandingkan aspek akademik $(0,406)$ dan non akademik $(0,475)$. Hal ini menunjukkan bahwa semakin baik program akademik dan reputasi dari Universitas Trisakti, maka semakin tinggi kepuasan mahasiswa. Hal ini mungkin terjadi karena alumni dari Fakultas Ekonomi dan Bisnis Universitas Trisakti merasa tidak terlalu sulit mendapatkan pekerjaan. Sebagaimana yang diuraikan oleh 
(Faupel-Badger, Nelson, \& Izmirlian, 2017) bahwa kemudahan mendapatkan pekerjaan bagi alumni akan meningkatkan kepuasan mahasiswa. Selain itu, reputasi Universitas Trisakti juga memudahkan calon mahasiswa untuk memilih Universitas yang mereka inginkan.

Hal ini sesuai dengan penelitian oleh (Skallerud, 2011) dan (Watjatrakul, 2014) ketika mengevaluasi proses pengambilan keputusan para orang tua dalam pemilihan sekolah, maka reputasi merupakan bagian penting dari kepuasan siswa dan orang tuanya. Begitu juga (Alhelalat, 2015) ketika menemukan bahwa dari beberapa factor yang mendorong siswa memilih sebuah PT, maka reputasi menjadi salah satu factor penting yang membantu proses pemilihan tersebut. Selanjutnya (Ali et al., 2016) dalam penelitiannya mengenai kualitas jasa di PT Malasyia memastikan bahwa reputasi menjadi salah satu factor yang mempengaruhi kepuasan mahasiswa. Akhirnya (Saleem, Moosa, Imam, \& Khan, 2017) menyimpulkan bahwa reputasi sebuah PT ternyata dapat memoderasi kepuasan mahasiswa. Semakin baik reputasi sebuah PT, maka semakin tinggi kepuasan mahasiswanya.

Selanjutnya berdasarkan hasil pengujian hipotesis kelima, ternyata Access tidak mempunyai pengaruh positif terhadap Student Satisfaction. Hal ini menunjukkan bahwa walaupun kinerja staff akademik baik, ketersediaan staff dalam merespon mahasiswa juga baik tetapi hal tersebut tidak meningkatkan kepuasan mahasiswa Universitas Trisakti. Hal ini dapat terjadi karena secara rata-rata hasil statistic deskriptif memperlihatkan bahwa kebanyakan mahasiswa merasa bahwa fasilitas akses dari Universitas Trisakti hanya lumayan memuaskan bagi mereka sehingga tidak mempengeruhi kepuasan mereka.

Hasil pengujian hipotesis keenam menyimpulkan bahwa Student Satisfaction mempunyai pengaruh positif terhadap Image Hal ini menunjukkan bahwa semakin tinggi kepuasan yang dirasakan mahasiswa Universitas Trisakti maka akan meningkatan image dari universitas tersebut. Hasil penelitian ini sesuai dengan penelitian (Ali et al., 2016) mengenai peranan image pada PT di Malasyia. Begitu juga dengan penelitian yang dilakukan di Norwagia oleh (Helgesen \& Nesset, 2007) ketika mengevaluasi peranan kepuasan mahasiswa sebagai factor peningkatan image (citra) sebuah PT.

Sebagaimana telah dijelaskan diatas, ternyata kepuasan konsumen dan image (citra) tidak mempunyai pengaruh positif terhadap loyalitas mahasiswa. Walaupun hasil ini cukup mengherankan, tetapi hal ini memang mungkin saja terjadi. Sehingga dapat dikatakan walaupun mahasiswa selama ini puas terhadap Universitas Trisakti dan juga berpendapat bahwa citra Universitas Trisakti masih baik, tetapi mereka merasa tidak perlu bersikap loyal terhadap trisakti. Mahasiswa merasa tidak perlu merekomendasikan PT mereka kepada teman dan keluarga. Hasil penelitian ini tidak sesuai dengan temuan dari (Helgesen \& Nesset, 2007) dan (Ali et al., 2016) yang menemukan bahwa image (citra) PT akan mempengaruhi loyalitas mahasiswa. 


\section{PENUTUP}

Berdasarkan hasil uji hipotesa, dapat disimpulkan bahwa academic aspect, non academic aspect dan reputation mempunyai pengaruh positif yang significant terhadap student satisfaction, dan selanjutnya student satisfaction memberikan pengaruh positif terhadap image Universitas Trisakti. Sedangkan program issues dan access tidak mempunyai pengaruh positif terhadap student satisfaction. Begitu juga student satisfaction dan Image tidak mempunyai pengaruh positif terhadap student loyalty.

Berdasarkan hasil penelitian diatas, maka sangat penting bagi Fakultas Ekonomi, Universitas Trisakti untuk memperkuat reputasinya dengan memperbaiki layanan dari berbagai sudut, seperti memfasilitasi mahasiswa dan dosen agar lebih mudah berkomunikasi, memperkuat hubungan dengan industry sehingga memperbesar kemungkinan mahasiswa untuk mendapat pekerjaan. Selain itu, juga sangat penting untuk meningkatkan pelayanan pada aspek akademik dan non akademik agar kepuasan mahasiswa lebih terjaga.

\section{DAFTAR PUSTAKA}

Abdullah, F. (2005). HEdPERF versus SERVPERF. Quality Assurance in Education, 13(4), 305-328. https://doi.org/10.1108/09684880510626584

Abdullah, F. (2006a). Measuring service quality in higher education: HEdPERF versus SERVPERF. Marketing Intelligence \& Planning, 24(1), 31-47. https://doi.org/10.1108/02634500610641543

Abdullah, F. (2006b). The development of HEdPERF: a new measuring instrument of service quality for the higher education sector. International Journal of Consumer Studies, 30(6), 569-581. https://doi.org/10.1111/j.1470-6431.2005.00480.x

Alhelalat, J. A. (2015). Consumer behaviour analysis of hospitality students' evaluation and satisfaction with their universities. Tourism and Hospitality Management, 21(2), 127-143. https://doi.org/10.20867/thm.21.2.2

Ali, F., Zhou, Y., Hussain, K., Nair, P. K., \& Ragavan, N. A. (2016). Does higher education service quality effect student satisfaction, image and loyalty? Quality Assurance in Education, 24(1), 70-94. https://doi.org/10.1108/QAE-02-20140008

Alves, H., \& Raposo, M. (2010). The influence of university image on student behaviour. International Journal of Educational Management, 24(1), 73-85. https://doi.org/10.1108/09513541011013060

Arpan, L. M., Raney, A. a, \& Zivnuska, S. (2003). A cognitive approach to understanding university image employee relations; treatment of the environment; and. Corporate Communications: An International Journal, 8(2), 97-113. https://doi.org/10.1108/13563280310474535

Azoury, N., Daou, L., \& Khoury, C. El. (2014). University image and its relationship to student satisfaction- case of the Middle Eastern private business schools. International Strategic Management Review, 2(1), 1-8. https://doi.org/10.1016/j.ism.2014.07.001 
Baruch, Y., \& Sang, K. J. C. (2012). Predicting MBA graduates' donation behaviour to their alma mater. Journal of Management Development, 31(8), 808-825. https://doi.org/10.1108/02621711211253268

Brochado, A. (2009). Comparing alternative instruments to measure service quality in higher education. Quality Assurance in Education, 17(2), 174-190. https://doi.org/10.1108/09684880910951381

Dehghan, A., Dugger, J., Dobrzykowski, D., \& Balazs, A. (2014). The antecedents of student loyalty in online programs. International Journal of Educational Management, 28(1), 15-35. https://doi.org/10.1108/IJEM-01-2013-0007

DeShields, O. W., Kara, A., \& Kaynak, E. (2005). Determinants of business student satisfaction and retention in higher education: applying Herzberg's two-factor theory. International Journal of Educational Management, 19(2), 128-139. https://doi.org/10.1108/09513540510582426

EFFAZIELA MOHAMAD TAHAR. (2008). Expectation and Perception of Posgraduate Students for Service Quality in Utm, (June).

Faupel-Badger, J. M., Nelson, D. E., \& Izmirlian, G. (2017). Career satisfaction and perceived salary competitiveness among individuals who completed postdoctoral research training in cancer prevention. PLoS ONE, 12(1), 1-14. https://doi.org/10.1371/journal.pone.0169859

Fernandes, C., Ross, K., \& Meraj, M. (2013). Understanding student satisfaction and loyalty in the UAE HE sector. International Journal of Educational Management, 27(6), 613-630. https://doi.org/10.1108/IJEM-07-2012-0082

Han, H., \& Ryu, K. (2009). The Roles of the Physical Environment, Price Perception, and Customer Satisfaction in Determining Customer Loyalty in the Restaurant Industry. Journal of Hospitality \& Tourism Research, 33(4), 487-510. https://doi.org/10.1177/1096348009344212

Helgesen, Ø., \& Nesset, E. (2007). What accounts for students' loyalty? Some field study evidence. International Journal of Educational Management, 21(2), 126143. https://doi.org/10.1108/09513540710729926

Hill, F. M. (1995). Managing service quality in higher education: the role of the student as primary consumer. Quality Assurance in Education, 3(3), 10-21. https://doi.org/10.1108/09684889510093497

Jancey, J., \& Burns, S. (2013). Institutional factors and the postgraduate student experience. Quality Assurance in Education, 21(3), 311-322. https://doi.org/10.1108/QAE-Nov-2011-0069

Kuh, G. D., \& Hu, S. (2001). The effects of student-faculty interaction in the 1990s. The Review of Higher Education, 24(3), 309-332. https://doi.org/10.1353/rhe.2001.0005

Narteh, B. (2013). Determinants of students' loyalty in the Ghanaian banking industry. The TQM Journal, 25(2), 153-169. https://doi.org/10.1108/17542731311299591

Nguyen, N., \& LeBlanc, G. (1998). The mediating role of corporate image on customers' retention decisions: an investigation in financial services. International Journal of Bank Marketing, 16(2), 52-65. https://doi.org/10.1108/02652329810206707

Nguyen, N., \& LeBlanc, G. (2001). Image and reputation of higher education institutions in students' retention decisions. International Journal of Educational Management, 15(6), 303-311. https://doi.org/10.1108/EUM0000000005909 
Oliver, R. (1999). Whence Consumer Loyalty. The Journal of Marketing, Fundamental Issues and Directions for Marketing, 63, 33-44.

Oliver, R. L., Rust, R. T., \& Varki, S. (1997). Customer Deli \& t : Managerial Ir \& ght Foundations, Findings , and. Journal of Retailing, 73(3), 311-336.

Petruzzellis, L., Maria D 'uggento, A., Romanazzi, S., Douglas, J., Douglas, A., Barnes, B., ... Hameed, A. (2013). Student satisfaction and impact of leadership in private universities. The TQM Journal , 25(4), 399-416. https://doi.org/10.1108/17542731311314881

Saleem, S. S., Moosa, K., Imam, A., \& Khan, R. A. (2017). Service Quality and Student Satisfaction : The Moderating Role of University Culture, Reputation and Price in Education Sector of Pakistan. Iranian Journal of Management Studies, 10(1), 237258. https://doi.org/10.22059/ijms.2017.217335.672304

Sharif, K., \& Kassim, N. M. (2012). Non-academic service quality: comparative analysis of students and faculty as users. Journal of Marketing for Higher Education, 22(1), 35-54. https://doi.org/10.1080/08841241.2012.705793

Skallerud, K. (2011). School reputation and its relation to parents' satisfaction and loyalty. International Journal of Educational Management, 25(7), 671-686. https://doi.org/10.1108/09513541111172081

Smith, G., Smith, A., \& Clarke, A. (2007). Evaluating service quality in universities: a service department perspective. Quality Assurance in Education, 15(3), 334-351. https://doi.org/10.1108/09684880710773200

Sultan, P., \& Yin Wong, H. (2010). Service quality in higher education - a review and research agenda. International Journal of Quality and Service Sciences, 2(2), 259272. https://doi.org/10.1108/17566691011057393

Sultan, P., \& Yin Wong, H. (2013). Antecedents and consequences of service quality in a higher education context. Quality Assurance in Education, 21(1), 70-95. https://doi.org/10.1108/09684881311293070

Watjatrakul, B. (2014). Factors affecting students' intentions to study at universities adopting the "student-as-customer" concept. International Journal of Educational Management, 28(6), 676-693. https://doi.org/10.1108/IJEM-09-2013-0135

Xiaoyun Han, Kwortnik, R. J., \& Chunxiao Wang. (2008). Service Loyalty. Journal of Service Research, 11(1), 22-42. https://doi.org/10.1177/1094670508319094 